\title{
Synthesis and the Structural Transformation of fcc to $h c p$ in Ni-Graphene Nanocomposite by Simple Chemical Route via Sonication
}

\author{
N. K. Mahale, ${ }^{1}$ R. D. Ladhe, ${ }^{2}$ S. B. Attarde, ${ }^{1}$ and S. T. Ingle ${ }^{1}$ \\ ${ }^{1}$ School of Environmental and Earth Sciences, North Maharashtra University, Jalgaon 425001, India \\ ${ }^{2}$ Department of Physics, School of Physical Sciences, North Maharashtra University, Jalgaon 425001, India
}

Correspondence should be addressed to S. T. Ingle; sopan.ingle@gmail.com

Received 7 February 2014; Revised 28 May 2014; Accepted 30 May 2014; Published 23 June 2014

Academic Editor: Raphael Schneider

Copyright (C) 2014 N. K. Mahale et al. This is an open access article distributed under the Creative Commons Attribution License, which permits unrestricted use, distribution, and reproduction in any medium, provided the original work is properly cited.

\begin{abstract}
We report the synthesis and structural transformation of $f c c$ to $h c p$ in Ni-graphene (Ni-Gr) composite by simple chemical route via sonication. The syntheses of $\mathrm{Ni}-\mathrm{Gr}$ composite by simultaneous reduction method, and the effect of different composition ratio on morphology and crystal structure were examined in our present study. The results indicated that the graphene ratio played an important role in crystal structure and $d$-spacing in nickel crystals. Different compositions have shown different behavior. The nanonickel clusters of various shapes with coated graphene and decorated as nickel on graphene sheets are observed. The synthesized composites were characterized using X-ray diffraction (XRD), field emission scanning electron microscopy (FE-SEM), and transmission electron microscope (TEM). The XRD patterns indicated crystal lattice modifications in some composites while composites with a higher graphene ratio produced very small crystals with uniform lattice parameter and $d$-spacing. FE-SEM images indicated the growth of Datura fruit like shapes of nickel clusters in higher composition of nickel while the composites with least concentration of nickel were composed of cubical nanoparticles grown on graphene sheets. TEM analysis revealed many $\mathrm{Ni}$ nanoparticles surrounding the smooth petals like surface of graphene, with average diameters of spiky nickel nanoparticles being about $50 \mathrm{~nm}$ and $124 \mathrm{~nm}$, respectively, on $200 \mathrm{~nm}$ of scale.
\end{abstract}

\section{Introduction}

By virtue of large surface to volume ratio, nanoparticles are currently enjoying broad aspects of research. Graphene's importance has been well accepted after exploration of its extraordinary physical properties of high conductivity, high surface area, and exceptional mechanical properties. The common methods of graphene production includes micromechanical exfoliation, thermal expansion of graphite [1-3], chemical vapor deposition $[4,5]$, and solution-based chemical reduction of exfoliated graphite oxide [4, 6-9]. At the same time in the world of material science, nanonickel is also having unique place with variety of applications in chemical cell, batteries, nanoelectronics, and fuel cell and especially as a catalyst; but both graphene and nickel have excellent performances as a composite material in supercapacitors, photovoltaics, and batteries [4]. Moreover nickel nanoparticles have wide scope in different disciplines including magnetic fluids [10], data storage [11], biotechnology [12], catalysis $[13,14]$, and magnetic resonance imaging $[15,16]$; it is also applicable as catalysts for hydrogenation of nitrobenzene [17] and thermal decomposition of ammonium perchlorate [18]. Many methods have been used to synthesize the metal nanoparticles, namely, chemical reduction [19-28], photochemical reduction $[29,30]$, sonochemical method [31], microemulsion technique [32], polyol process [33, 34], alcohol reduction [35], heat evaporation [36, 37], and electrochemical reduction $[27,28]$. Though nickel nanoparticles are synthesized by reduction of metal salts using reducing agents as $\mathrm{NaBH}_{4}$, hydrazine, and polyols, these processes can produce stable nanoparticles without agglomeration, but particle surfaces are often found to be rough and exhibit spiky surface morphology [38].

In this work we have attempted to study higher control over structural, morphological, and compositional properties 
with a high specific surface area and overall composition and control over their resultant catalytic and other physical properties.

\section{Experimental Details}

2.1. Preparation of Graphite Oxide. Graphite oxide was prepared with modified Hummer's method, by stirring $100 \mathrm{mg}$ graphite powder and $50 \mathrm{mg}$ sodium nitrate in $3 \mathrm{~mL}$ sulphuric acid. The above suspension was kept in round bottom flask (RBF) under ice bath with vigorous agitation, and RBF was kept under ice bath with addition of potassium permanganate $\left(\mathrm{KMnO}_{4}\right)$ over 30 minutes. The rate of addition of $\mathrm{KMnO}_{4}$ was maintained enough to control the temperature of suspension from exceeding $20^{\circ} \mathrm{C}$. After 30 minutes ice bath was removed and the temperature was allowed to rise up to $35^{\circ} \mathrm{C}$ for 2 hours and as the reaction progressed the mixture became a brownish grey paste. At the end of 2 hours, $100 \mathrm{~mL}$ distilled water was added drop by drop for 15 minutes and the temperature of the reaction was maintained at $90-95^{\circ} \mathrm{C}$. After distilled water addition, the suspension turned brown in color, and then $100 \mathrm{~mL} 30 \%$ hydrogen peroxide $\left(\mathrm{H}_{2} \mathrm{O}_{2}\right)$ was added to minimize the concentration of residual permanganate and manganese dioxide to colorless soluble manganese sulfate. After treatment with $\mathrm{H}_{2} \mathrm{O}_{2}$, the suspension turned bright yellow color.

The filtration and washing of graphite oxide (GO) are very difficult due to its lower molecular size and suspension which takes lot of time to settle, in case of filtration clogging of filter paper makes it messy. To get rid of this problem the best way we adopted by transferring synthesized suspension in separating funnel of $500 \mathrm{~mL}$ capacity and kept it aside up to settling; after that we got a transparent layer upper layer and the bottom layer filled of graphite oxide suspension and then separated these two layers by transferring the GO suspension slowly without mixing the upper one with a lower layer in another separating funnel. For collection of the GO paste, centrifuged it at 9000 RPM for 15-20 min. The supernatant from centrifuged was discarded and collected the graphite oxide. The GO paste was washed by $10 \%$ hydrochloric acid and subsequently by distilled water till it becomes neutral ( $\mathrm{pH} 7$ ); mother liquor was tested by atomic absorption spectrophotometer (Thermo) to ensure the filtrate is completely manganese free and then transformed it into powder form by evaporating the water. The quantity of graphite oxide required for the whole experiment was produced under different batches with the same method.

2.2. Synthesis of Nanonickel Graphene Composite. Individual nickel nanoparticles were synthesized by reduction method using hydrazine hydrate $\left(\mathrm{N}_{2} \mathrm{H}_{4} \cdot \mathrm{H}_{2} \mathrm{O}\right)$. The use of hydrazine hydrate in aerobic condition leads to the formation of nickel oxide nanoparticles by chelation; Ni nanoparticles formation takes place through reduction of $\mathrm{Ni}^{+2}$ by $\mathrm{N}_{2} \mathrm{H}_{4} \cdot \mathrm{H}_{2} \mathrm{O}$ and here molar ratio of $\mathrm{Ni}: \mathrm{N}_{2} \mathrm{H}_{4}: \mathrm{NaOH}$ must be $1: 6.4: 5.1$; out of these trio, if ratio of $\mathrm{NaOH}$ and $\mathrm{N}_{2} \mathrm{H}_{4} \cdot \mathrm{H}_{2} \mathrm{O}$ is disturbed, then the nickel hydrazine chloride complex forms. In this case first the bis- and trisnickel hydrazine chloride complex of purple and blue color are formed and then at $60-70^{\circ} \mathrm{C}$ they get reduced in presence of sodium hydroxide.

We decorated nickel nanoparticles on graphene by simultaneous sonication and reduction of nickel salt solution and graphite oxide; this method is more facile than conventional. Total of nine composites were prepared of different ratios of $\mathrm{Ni}: \mathrm{Gr}$, that is, $9: 1,8: 2,7: 3,6: 4,5: 5,4: 6,3: 7,2: 8$, and $1: 9$. As said above the molar ratio of the reactant was maintained except that the quantity of hydrazine hydrate was kept constant for all composites, that is, $10 \mathrm{~mL}$. Hydrazine hydrate $\left(\mathrm{N}_{2} \mathrm{H}_{4} \cdot \mathrm{H}_{2} \mathrm{O}\right)$ was used to reduce $\mathrm{Ni}^{+2}$ ion solution of various concentrations. $100 \mathrm{~mL}$ reagent-grade nickel chloride solution was prepared in water produced by a Milli-Q SP Ultrapure-Water Purification System; all used reagents were of analytical grade provided by Fisher Scientific Company. The sodium hydroxide and nickel chloride solutions of various concentrations were prepared as given in Table 1, and the quantity of graphite oxide was suspended in sodium hydroxide solution for uniform dispersion it was sonicated. The $10 \mathrm{~mL}$ hydrazine hydrate was taken in Erlenmeyer conical flask of $250 \mathrm{~mL}$ capacity and kept in sonicator bath (750 watts, $50 \mathrm{kHz}$, Ultrasonic cleaner, Lab Hosp, Mumbai); when the temperature in sonicator reached $45-50^{\circ} \mathrm{C}$, drop by drop addition of graphite oxide suspended sodium hydroxide and nickel chloride was started simultaneously and sonicated throughout the experiment. First the bis- and trisnickel hydrazine chloride complex of purple and blue color are formed at $60-70^{\circ} \mathrm{C}$; within 5-10 seconds solution turns black and it represents the formation of metal nickel nanoparticles. Being sonicated the aggregation of the particles was avoided. After finishing the reaction the composites were collected by centrifugation at $9000 \mathrm{rpm}$, paste was washed several times to make it free of base and nonreacted material. On achieving the neutral $\mathrm{pH}$ of composite paste it was transferred to Petri plates, allowed to dry, and then stored in cramped vials.

2.3. Characterization of Composites. The XRD patterns were obtained using the Brucker D8 Advance powder diffractometer operating in the reflection mode with $\mathrm{CuKa}$ radiation $(40 \mathrm{kV}, 40 \mathrm{~mA})$ and diffracted beam monochromator, using a step scan mode with the step of 0.020 and $0.5 \mathrm{~s}$ per step. Divergence slit 1.200 and antiscatter slit 0.600 were used. Diffraction patterns of powders were compared with ICCD reference database. The Scherrer equation was applied to estimate a crystallite size. The SEM micrographs were obtained using Hitachi High Tech S-4800 Type II equipped with EDX Brucker-X Flash Detector 5030. The TEM micrographs were analyzed on Philips CM200 TEM, having operating voltage range of $20-200 \mathrm{kv}$ with resolution: $2.4 \AA$. The powder samples were studied in native form without coating by conductive metal layers. The sample for electron microscopy was prepared by dispersing the powder in propanol by sonication and applying a drop of very dilute suspension on carbon-coated grids. The suspensions were dried by slow evaporation at ambient temperature. 
TABLE 1: Chemical composition applied for composite synthesis.

\begin{tabular}{lcccc}
\hline Composite & Graphite oxide $(\mathrm{gm})$ & $\begin{array}{c}\mathrm{NiCl}_{2} \cdot 6 \mathrm{H}_{2} \mathrm{O} \\
\text { \%w/v (aq.) }\end{array}$ & $\begin{array}{c}\mathrm{NaOH} \\
\text { \%w/v }(\mathrm{aq} .)\end{array}$ & $\mathrm{N}_{2} \mathrm{H}_{4} \cdot \mathrm{H}_{2} \mathrm{O}(\mathrm{mL})$ \\
\hline A & 0.1 & 3.644 & 0.15 & 0.13 \\
B & 0.2 & 3.239 & 0.11 & 10 \\
C & 0.3 & 2.834 & 0.010 & 10 \\
D & 0.4 & 2.429 & 0.08 & 10 \\
E & 0.5 & 2.024 & 0.06 & 10 \\
F & 0.6 & 1.619 & 0.05 & 10 \\
G & 0.7 & 1.214 & 0.03 & 10 \\
H & 0.8 & 0.809 & 0.01 & 10 \\
I & 0.9 & 0.409 & & 10 \\
\hline
\end{tabular}

\section{Result and Discussion}

3.1. X-Ray Diffraction Study. Figure 1 shows the XRD pattern of composites A to $\mathrm{H}$. As shown in the figure peaks can be indexed to face centered cubic phase (space group Fm-3m (225)) of Ni JCPDS number 01-077-9326. The XRD clearly showed that, as the $\mathrm{Ni}$ ratio decreased in composite ratio, the position and intensities of the XRD peaks are varied, possibly due to their size and morphology. The sharp peaks demonstrated that the synthesized nickel is well crystallized. The FE-SEM results showed that the graphene oxide or graphite oxide percentage played an important role in the final morphology of Ni-nanocrystal. It should be noted here that such a novel morphology has been reported earlier, and we are the first to introduce the new morphologies in composite regime. The FE-SEM results showed that the nickel nanoparticles may grow like cube as the graphite oxide percentage is increased. The XRD results of composites formed at various compositions; out of them most has showed high intensity at $43.5^{\circ}(2 \theta)$ that evidently confirmed the growth of nanocubes. Composites $\mathrm{A}$ and $\mathrm{B}$ have almost constant lattice parameter. $\mathrm{A}$ has $13.0 \AA$ while $\mathrm{B}$ has $8.75 \AA$, but the composite $\mathrm{C}$ shows the $h c p$ phases $a=b=3.6$ and $c=1.78$. Composite $\mathrm{D}$ has normally grown the nickel nanoparticles with constant lattice parameter. Lattice expansion can be seen in all composites except for composite A, though there are some composites with different parameters, but either lattice distortion or expansion is obvious in the composites. According to previous reports lattice distortion in various nanocrystalline materials processed using different methods is revealed by significant change in the lattice parameter $[39,40]$.

Composites $\mathrm{G}$ and $\mathrm{C}$ show higher degree of lattice distortion as compared to the other composites. Composites $\mathrm{G}$ and $\mathrm{C}$ with $h c p$ regime can be understood with the work explained by Datta et al. [41]. They have reported that the structural transformation of $f c c$ to $h c p$ in $\mathrm{Ni}(\mathrm{Si})$ below the critical size of $\sim 10 \mathrm{~nm}$ by the mechanical instability concept calculations based on the equation of state shows $37 \%$ reduction in tetragonal shear modulus of nanocrystalline $f c c$ $\mathrm{Ni}(\mathrm{Si})$ at onset of transformation suggesting defect induced

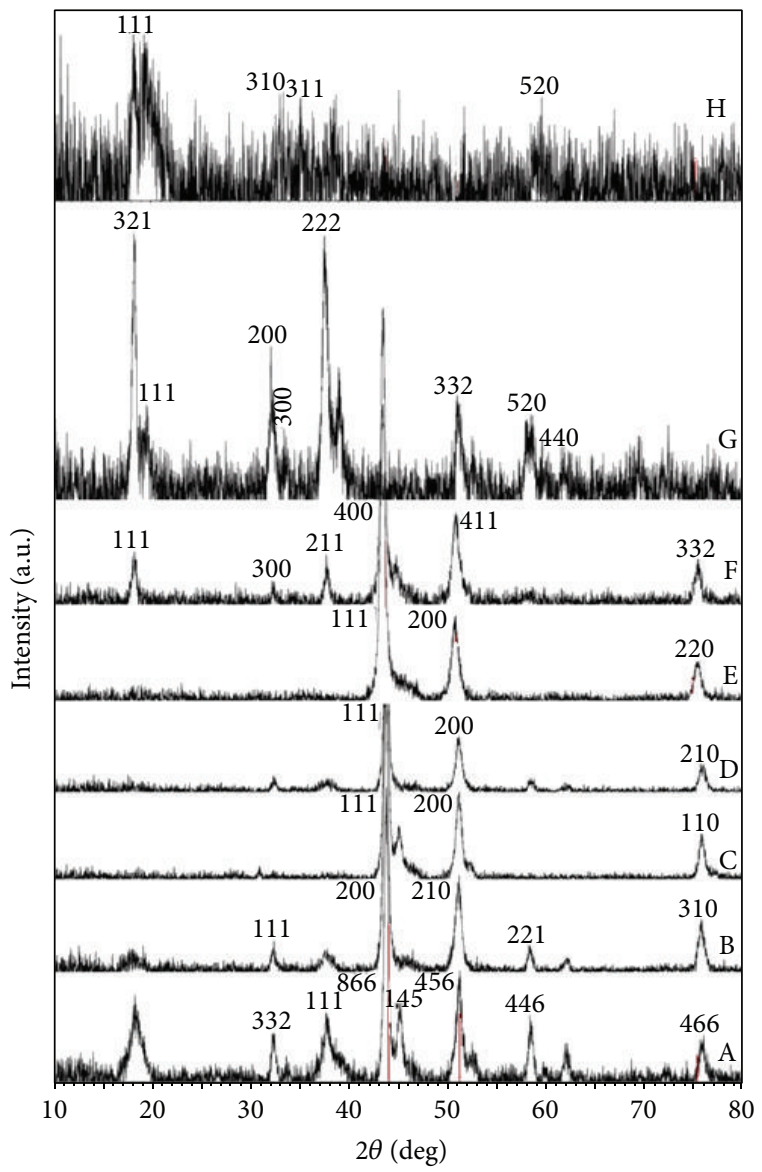

FIGURE 1: XRD pattern of composites A to $\mathrm{H}$.

melting of $f c c \mathrm{Ni}(\mathrm{Si})$ to amorphous structure of zero shape modulus which is expected to be relaxed to hcp structure of molar volume of $7.57 \mathrm{~cm}^{3} / \mathrm{moL}$ and is in good agreement with the molar volume of liquid at the melting point of $\mathrm{Ni}$. According to Chatterjee et al. [42], the expansion of lattice parameter also has been detected in nanocrystalline bcc $(\mathrm{Cr}$, 
$\mathrm{Fe}$, and $\mathrm{Nb})$ and $f c c(\mathrm{Ni}, \mathrm{Cu}, \mathrm{Ag}$, and $\mathrm{Pd})$ metal synthesized using different approaches [43].

In case of crystal size and molar volume of the composite, result shows crystal size reduced greatly with increasing graphene ratio. As per the crystal size determined by Scherrer equation the lowest crystal size is observed at composite $\mathrm{H}$, that is, $0.07 \AA$. The refinement of crystal size has been explained by considering the presence of a stress field at the core due to presence of vacancy or vacancy cluster situated at grain boundary in nanocrystalline material which mainly depends on the volume fraction of the interface that is inversely related to crystallite size [44].

3.2. Scanning Electron Microscopic Study. Scanning electron micrograph of the composites can be seen in Figure 2. Figure 2(a) shows effect of simultaneous reduction of $\mathrm{Ni}^{+2}$ and GO in composite A. On an average of $50 \mathrm{~nm}$ spherical particle embedded in graphene coating. The particle formation of both $\mathrm{Ni}$ and graphene at the same time has made uniform coating on one another. At microlevel the nanoclusters of the composite are observed. In case of composite B the increased amount of graphene can be seen apparently in Figure 2(b). The clusters are grown like Datura fruit; spiky nickel nanoparticles spherical cluster is surrounded by petals of graphene. Not only the clusters are on graphene but also the metal nanoparticles are embedded in nanopetals of graphene. Thin film has covered the nanoclusters of nickel containing both spherical and spiky nanoparticles.

The thick film of graphene on nickel clusters is more vivid in scanning electron micrograph of composite $\mathrm{C}$ in Figure 2(c); it is the effect of higher percentage of graphene in the Ni:Gr (3:7) ratio. Every Ni particle gets embedded as soon as it is formed and a very good and uniform covering of graphene is observed in composite C. About all the nanoclusters are of the same size, interconnected, and covered by graphene. With reduction in $\mathrm{Ni}^{+2}$ ions and increase in graphite oxide, the cluster size increased and spiky shape of Ni nanoparticles tends towards being more spherical. The graphene and cluster contacts are also thick compared to the previous composites. The coating of the graphene over nickel nanoclusters has become heavier and thick; the previous composites have shown nearly transparent coating over nickel nanoclusters.

The increasing amount of graphite oxide and the reduced $\mathrm{Ni}$ is showing great impact on the site of the nanoclusters growth in composite E. The nickel nanoparticle growth is preferred more on the edges of the graphene sheet. This is maybe due to the fact that the site for nucleation provided by hydroxyl group is present at the verge of reduced graphite oxide. This composite having 50:50 proportion of $\mathrm{Ni}$ and graphene shows that the epoxy, hydroxyl, and pairwise carboxyl groups are available for further reaction with graphite oxide. A single formation at the edge and its magnetic attraction gives rise to cluster formation up to some extent. The composite $\mathrm{F}$ that is, $6: 4$, in this composite nickel nanoclusters are formed like a chain of clusters connected by graphene, can be seen in Figure 2(f). The graphene coating of a cluster avails the site for nucleation of another cluster and so on. Such behavior may reduce the resistance in the composite and could serve as a better catalyst. Around 40$100 \mathrm{~nm}$ size and sphere were formed on graphene surface; not only surface edge but also all the available space was used by nickel nanoparticles. This ratio $7: 3$, that is, composite $\mathrm{G}$, is more perfect from the point of crystal lattice and $d$ spacing though it has low quantity of nickel, but it has occupied nearly all the surface available with graphene sheet. The largest diameter of nickel nanoparticles was found to be $573 \mathrm{~nm}$. The spike of nanonickel pixels/cubes has seen on the corners of graphene sheet. As in the previous composites the graphene was showing Datura fruit like morphology along with $\mathrm{Ni}$ nanoparticles, but in composite graphene show the cabbage like morphology and $\mathrm{Ni}$ nanocubes of size ranging from 12 to $100 \mathrm{~nm}$ on graphene surface. In composite G approximately all the sheets of graphene and maximum surface of sheets have been covered by cubes of $\mathrm{Ni}$. In composite I, that is, $\mathrm{Ni}: \mathrm{Gr}(1: 9)$, sporadically scattered growth of nickel nanoparticles has occurred. The amount of nickel in ratio that is $10 \%$ is not enough to cover the large surface area of graphene.

\subsection{Transmission Electron Microscopic Study. A TEM image} recorded from two spherical clusters of spiky nickel on the thick surface of graphene is displayed in Figure 3(a). Apparently there are many nanoparticles surrounding the smooth petals like surface of graphene; the average diameters of spiky nickel nanoparticles are about $50 \mathrm{~nm}$ and $124 \mathrm{~nm}$, respectively, on $50 \mathrm{~nm}$ of scale. Not only the clusters are on graphene but also the metal nanoparticles are embedded in nanopetals of graphene. This formation of the nickel nanoparticles was observed by FESEM and previously was confirmed by TEM. Figure 3(c) is the corresponding selected area electron diffraction pattern with the interplanar spacings of the nanoparticles being $2.5 \mathrm{~nm}$ and $5.4 \mathrm{~nm}$, consisting of the spacings of the (lllll 110 ) and ( $\left.\begin{array}{lll}2 & 0 & 0\end{array}\right)$ plane of nickel and graphene.

\section{Conclusions}

We have successfully synthesized and achieved structural transformation of $f c c$ to $h c p$ in Ni-graphene (Ni-Gr) composite by simple chemical route via sonication. As a result we found nonmagnetic nickel and also decorated the graphene clusters with $\mathrm{Ni}$ cubes and Datura fruit like morphologies by changing $\mathrm{GO}$ ratio in $\mathrm{Ni}$ : $\mathrm{Gr}$ composites. The composition of $\mathrm{Ni}^{+2}$ and $\mathrm{GO}$ and their effect on growth and morphology were investigated. The GO played a major role in formation of various microstructures of composite. The XRD pattern showed the formation of well crystallized nickel nanoparticles on smooth amorphous graphene surface. The FE-SEM and TEM images showed that the clusters and the coating of graphene over Ni nanoparticles are self-assembled by reduction and sonication process. The composites are prepared by hydrazine hydrate and sonication method which is one of its kind and significant morphologies have been synthesized and showed new material 


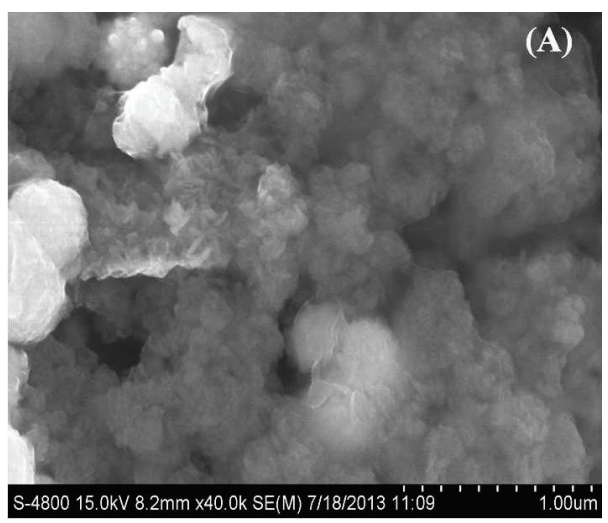

(a)

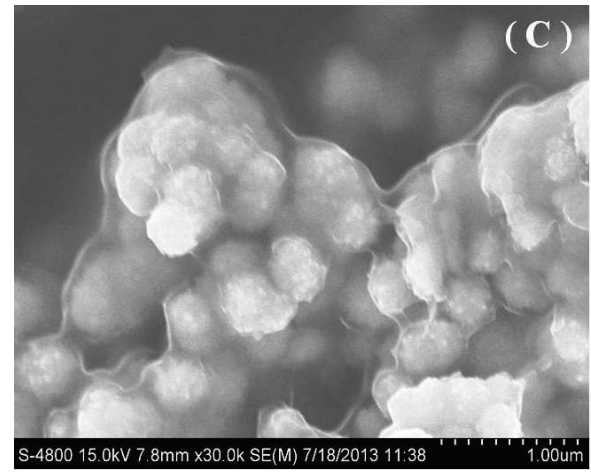

(c)

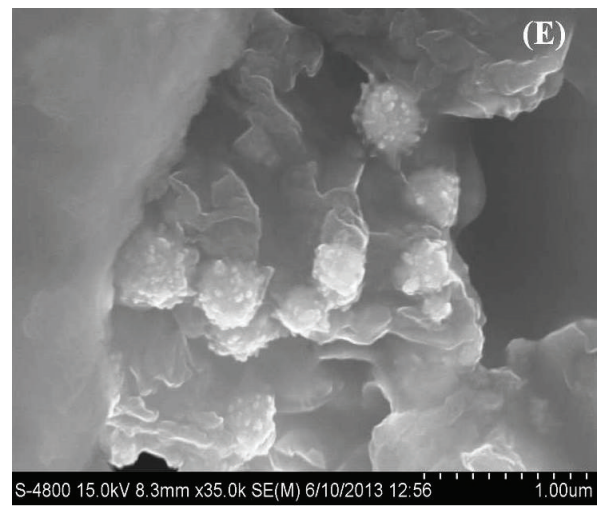

(e)

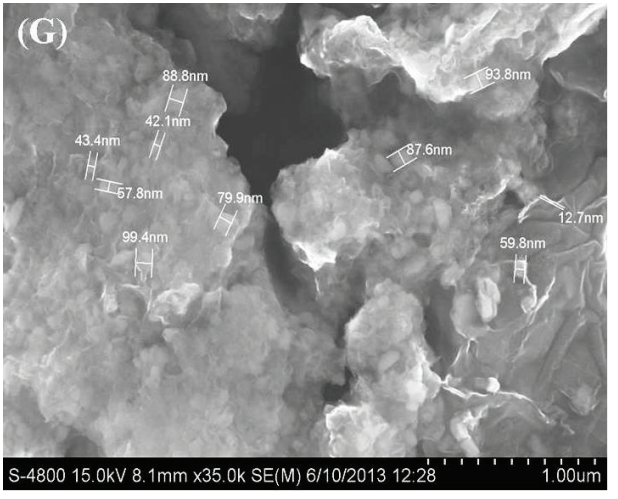

(g)

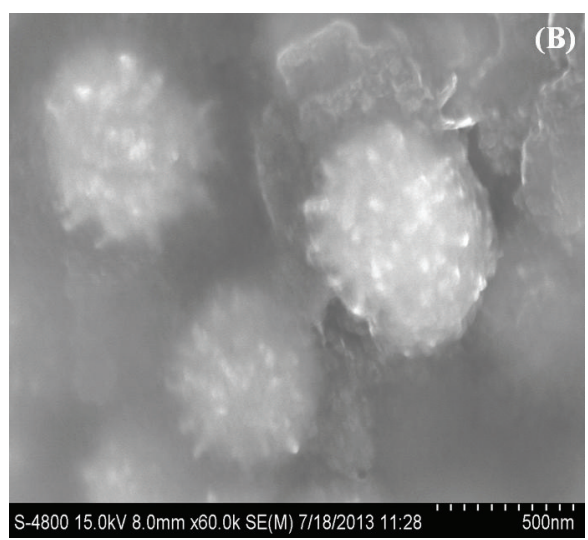

(b)

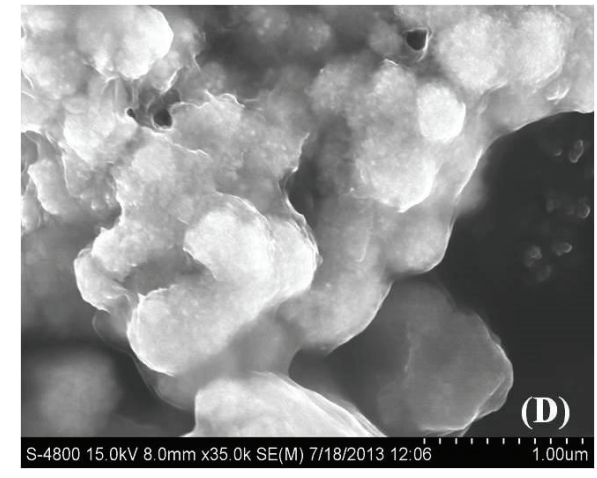

(d)

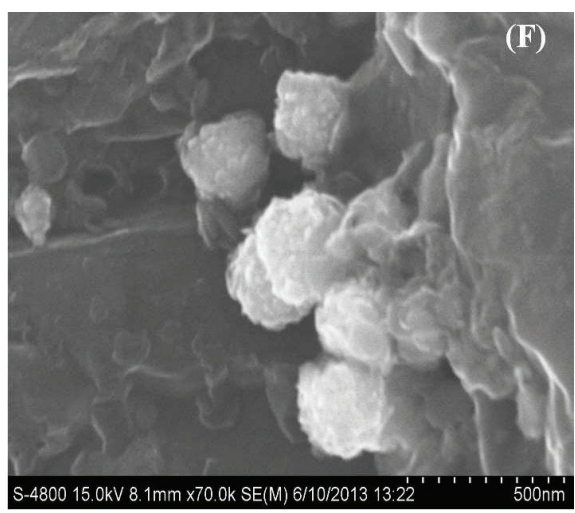

(f)

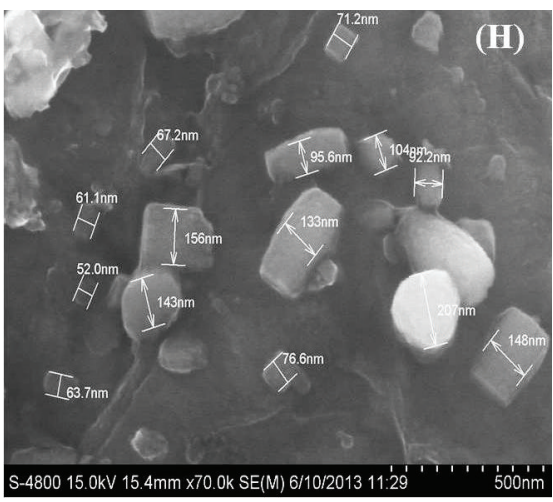

(h)

Figure 2: SEM micrograph of composites A (Ni $9: 1$ graphene), B (8:2), C (7:3), D (6:4), E (5:5), F (4:6), G (3:7), and H (2:8). 


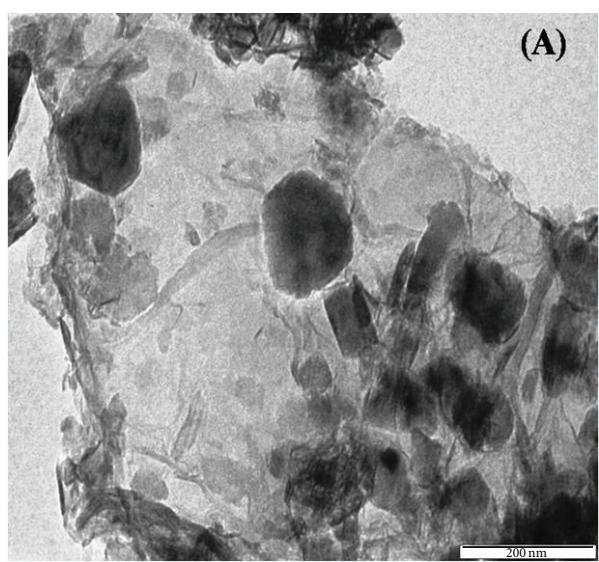

(a)

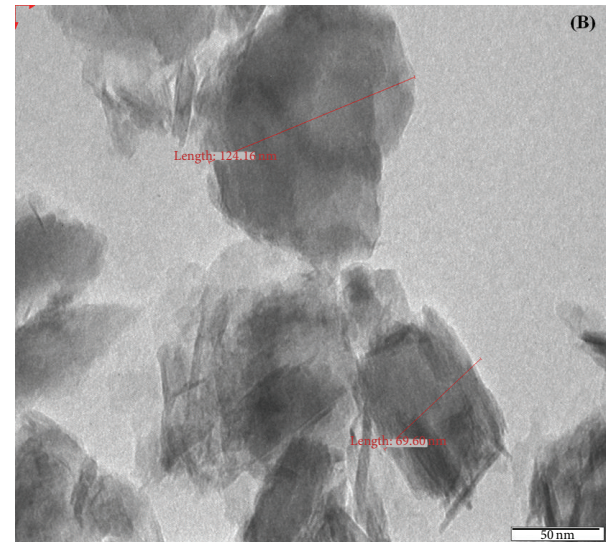

(b)

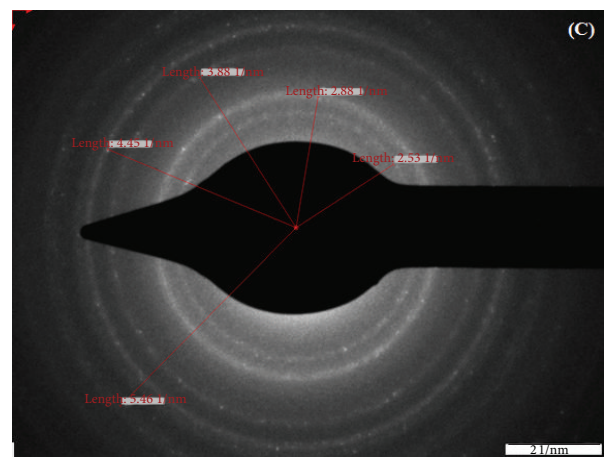

(c)

Figure 3: (a) TEM images of Ni nanoparticles surrounded by graphene in composite H. (b) Average diameters of nickel nanoparticles of composite H. (c) SAED of composite H.

for further variety of applications in chemical cell, batteries, nanoelectronics and fuel cell and especially as a catalyst.

\section{Conflict of Interests}

The authors declare that there is no conflict of interests regarding the publication of this paper.

\section{References}

[1] K. S. Novoselov, A. K. Geim, S. V. Morozov et al., "Electric field in atomically thin carbon films," Science, vol. 306, no. 5696, pp. 666-669, 2004.

[2] K. S. Kim, Y. Zhao, H. Jang et al., "Large-scale pattern growth of graphene films for stretchable transparent electrodes," Nature, vol. 457, no. 7230 , pp. 706-710, 2009.

[3] H. C. Schniepp, J.-L. Li, M. J. McAllister et al., "Functionalized single graphene sheets derived from splitting graphite oxide," Journal of Physical Chemistry B, vol. 110, no. 17, pp. 8535-8539, 2006.

[4] Z. Ji, X. Shen, G. Zhu, H. Zhou, and A. Yuan, "Reduced graphene oxide/nickel nanocomposites: facile synthesis, magnetic and catalytic properties," Journal of Materials Chemistry, vol. 22, no. 8, pp. 3471-3477, 2012.

[5] A. Reina, X. T. Jia, J. Ho et al., "Large area, few-layer graphene films on arbitrary substrates by chemical vapor deposition," Nano Letters, vol. 9, no. 1, pp. 30-35, 2009.
[6] S. Stankovich, D. A. Dikin, R. D. Piner et al., "Synthesis of graphene-based nanosheets via chemical reduction of exfoliated graphite oxide," Carbon, vol. 45, no. 7, pp. 1558-1565, 2007.

[7] X. B. Fan, W. C. Peng, Y. Li et al., "Deoxygenation of exfoliated graphite oxide under alkaline conditions: a green route to graphene preparation," Advanced Materials, vol. 20, no. 23, pp. 4490-4493, 2008.

[8] D. Li, M. B. Müller, S. Gilje, R. B. Kaner, and G. G. Wallace, "Processable aqueous dispersions of graphene nanosheets," Nature Nanotechnology, vol. 3, no. 2, pp. 101-105, 2008.

[9] H.-J. Shin, K. K. Kim, A. Benayad et al., "Efficient reduction of graphite oxide by sodium borohydride and its effect on electrical conductance," Advanced Functional Materials, vol. 19, no. 12, pp. 1987-1992, 2009.

[10] S. Chikazumi, S. Taketomi, M. Ukita et al., "Physics of magnetic fluids," Journal of Magnetism and Magnetic Materials, vol. 65, no. 2-3, pp. 245-251, 1987.

[11] D. Chiba, M. Sawicki, Y. Nishitani, Y. Nakatani, F. Matsukura, and $\mathrm{H}$. Ohno, "Magnetization vector manipulation by electric fields," Nature, vol. 455, no. 7212, pp. 515-518, 2008.

[12] A. K. Gupta and M. Gupta, "Synthesis and surface engineering of iron oxide nanoparticles for biomedical applications," Biomaterials, vol. 26, no. 18, pp. 3995-4021, 2005.

[13] A.-H. Lu, W. Schmidt, N. Matoussevitch et al., "Nanoengineering of a magnetically separable hydrogenation catalyst," Angewandte Chemie-International Edition, vol. 43, no. 33, pp. 4303-4306, 2004. 
[14] S. C. Tsang, V. Caps, I. Paraskevas, D. Chadwick, and D. Thompsett, "Magnetically separable, carbon-supported nanocatalysts for the manufacture of fine chemicals," Angewandte Chemi-International Edition, vol. 43, no. 42, pp. 56455649, 2004.

[15] S. Mornet, S. Vasseur, F. Grasset et al., "Magnetic nanoparticle design for medical applications," Progress in Solid State Chemistry, vol. 34, no. 2-4, pp. 237-247, 2006.

[16] Z. Li, L. Wei, M. Y. Gao, and H. Lei, "One-pot reaction to synthesize biocompatible magnetite nanoparticles," Advanced Materials, vol. 17, no. 8, pp. 1001-1005, 2005.

[17] R. Xu, T. Xie, Y. Zhao, and Y. D. Li, "Quasi-homogeneous catalytic hydrogenation over monodisperse nickel and cobalt nanoparticles," Nanotechnology, vol. 18, no. 5, Article ID 055602, 2007.

[18] C. L. Tang, L. P. Li, H. B. Gao, G. S. Li, X. Q. Qiu, and J. Liu, "Syntheses and catalytic performances of Ag-Ni bi-metals," Journal of Power Sources, vol. 188, no. 2, pp. 397-403, 2009.

[19] K.-S. Chou and C.-Y. Ren, "Synthesis of nanosized silver particles by chemical reduction method," Materials Chemistry and Physics, vol. 64, no. 3, pp. 241-246, 2000.

[20] C. Petit, P. Lixon, and M.-P. Pileni, "In situ synthesis of silver nanocluster in AOT reverse micelles," Journal of Physical Chemistry, vol. 97, no. 49, pp. 12974-12983, 1993.

[21] S. A. Vorobyova, A. I. Lesnikovich, and N. S. Sobal, "Preparation of silver nanoparticles by interphase reduction," Colloids and Surfaces A: Physicochemical and Engineering Aspects, vol. 152, no. 3, pp. 375-379, 1999.

[22] Z. Zhang, B. Zhao, and L. Hu, "PVP protective mechanism of ultrafine silver powder synthesized by chemical reduction processes," Journal of Solid State Chemistry, vol. 121, no. 1, pp. 105-110, 1996.

[23] I. M. Yakutik and G. P. Shevchenko, "Self-organization of silver nanoparticles forming on chemical reduction to give monodisperse spheres," Surface Science, vol. 566-568, no. 1-3, pp. 414-418, 2004.

[24] H. Huang and X. Yang, "Synthesis of polysaccharide-stabilized gold and silver nanoparticles: a green method," Carbohydrate Research, vol. 339, no. 15, pp. 2627-2631, 2004.

[25] Z. Zhang and M. Han, "Template-directed growth from small clusters into uniform silver nanoparticles," Chemical Physics Letters, vol. 374, no. 1-2, pp. 91-94, 2003.

[26] Y. Tan, Y. Wang, L. Jiang, and D. Zhu, "Thiosalicylic acidfunctionalized silver nanoparticles synthesized in one-phase system," Journal of Colloid and Interface Science, vol. 249, no. 2, pp. 336-345, 2002.

[27] Y.-C. Liu and L.-H. Lin, "New pathway for the synthesis of ultrafine silver nanoparticles from bulk silver substrates in aqueous solutions by sonoelectrochemical methods," Electrochemistry Communications, vol. 6, no. 11, pp. 1163-1168, 2004.

[28] G. Sandmann, H. Dietz, and W. Plieth, "Preparation of silver nanoparticles on ITO surfaces by a double-pulse method," Journal of Electroanalytical Chemistry, vol. 491, no. 1-2, pp. 7886,2000 .

[29] K. Mallick, M. J. Witcomb, and M. S. Scurrell, "Self-assembly of silver nanoparticles in a polymer solvent: formation of a nanochain through nanoscale soldering," Materials Chemistry and Physics, vol. 90, no. 2-3, pp. 221-224, 2005.

[30] S. Kéki, J. Török, G. Deák, L. Daróczi, and M. Zsuga, "Silver nanoparticles by PAMAM-assisted photochemical reduction of $\mathrm{Ag}^{+}$," Journal of Colloid and Interface Science, vol. 229, no. 2, pp. 550-553, 2000.
[31] Y. Mizukoshi, K. Okitsu, Y. Maeda, T. A. Yamamoto, R. Oshima, and Y. Nagata, "Sonochemical preparation of bimetallic nanoparticles of gold/palladium in aqueous solution," Journal of Physical Chemistry B, vol. 101, no. 36, pp. 7033-7037, 1997.

[32] K. Osseo-Asare and F. J. Arriagada, "Synthesis of nanosize particles in reverse microemulsions," Ceramic Transactions, vol. 12, pp. 3-16, 1990.

[33] L. K. Kurihara, G. M. Chow, and P. E. Schoen, "Nanocrystalline metallic powders and films produced by the polyol method," Nanostructured Materials, vol. 5, no. 6, pp. 607-613, 1995.

[34] R. S. Ningthoujam, N. S. Gajbhiye, and S. Sharma, "Reduction mechanism of $\mathrm{Ni}^{2+}$ into Ni nanoparticles prepared from different precursors: magnetic studies," Pramana, vol. 72, no. 3, pp. 577-586, 2009.

[35] H. H. Huang, X. P. Ni, G. L. Loy et al., "Photochemical formation of silver nanoparticles in poly( $N$-vinylpyrrolidone)," Langmuir, vol. 12, no. 4, pp. 909-912, 1996.

[36] C. H. Bae, S. H. Nam, and S. M. Park, "Formation of silver nanoparticles by laser ablation of a silver target in $\mathrm{NaCl}$ solution," Applied Surface Science, vol. 197-198, pp. 628-634, 2002.

[37] A. B. Smetana, K. J. Klabunde, and C. M. Sorensen, "Synthesis of spherical silver nanoparticles by digestive ripening, stabilization with various agents, and their 3-D and 2-D superlattice formation," Journal of Colloid and Interface Science, vol. 284, no. 2, pp. 521-526, 2005.

[38] A. Kumar, A. Saxena, A. De, R. Shankar, and S. Mozumdar, "Controlled synthesis of size-tunable nickel and nickel oxide nanoparticles using water-in-oil microemulsions," Advances in Natural Sciences: Nanoscience and Nanotechnology, vol. 4, no. 2, Article ID 025009, 2013.

[39] K. Lu, "Nanocrystalline metals crystallized from amorphous solids: nanocrystallization, structure, and properties," Materials Science and Engineering R: Reports, vol. 16, no. 4, pp. 161-221, 1996.

[40] K. Lu and Y. H. Zhao, "Experimental evidences of lattice distortion in nanocrystalline materials," Nanostructured Materials, vol. 12, no. 1-4, pp. 559-562, 1999.

[41] M. K. Datta, S. K. Pabi, and B. S. Murty, "Face-centered-cubic to hexagonal-close-packed transformation in nanocrystalline $\mathrm{Ni}(\mathrm{Si})$ by mechanical alloying," Journal of Materials Research, vol. 15, no. 7, pp. 1429-1432, 2000.

[42] P. P. Chatterjee, S. K. Pabi, and I. Manna, "An allotropic transformation induced by mechanical alloying," Journal of Applied Physics, vol. 86, no. 10, article 5912, 1999.

[43] B. S. Murty, M. K. Datta, and S. K. Pabi, "Structure and thermal stability of nanocrystalline materials," Sadhana, vol. 28, no. 1-2, pp. 23-45, 2003.

[44] M. K. Datta, S. K. Pabi, and B. S. Murty, "Thermal stability of nanocrystalline fcc and hcp $\mathrm{Ni}(\mathrm{Si})$ synthesized by mechanical alloying of $\mathrm{Ni}_{90} \mathrm{Si}_{10}$," Philosophical Magazine Letters, vol. 81, no. 2, pp. 77-84, 2002. 

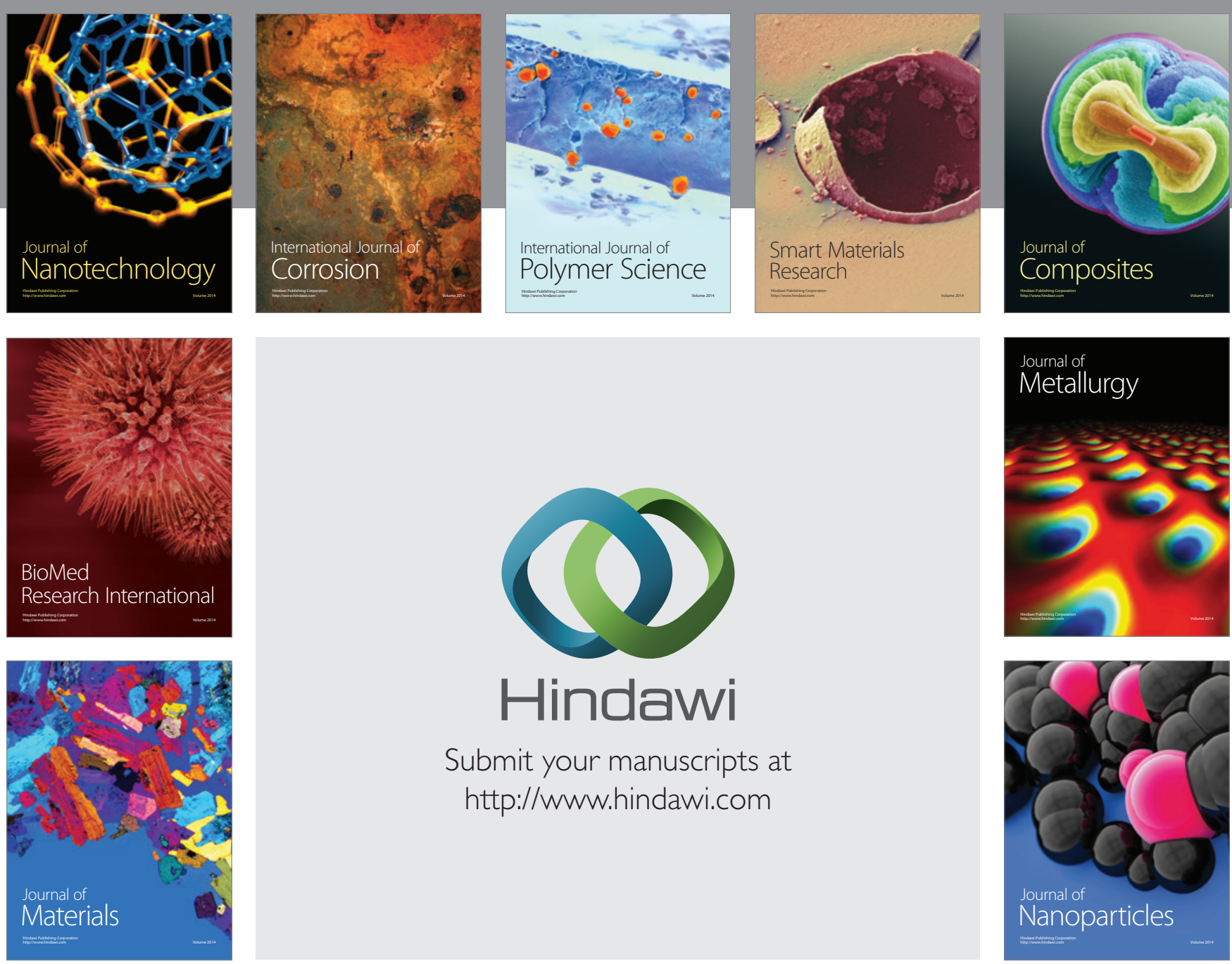

Submit your manuscripts at http://www.hindawi.com
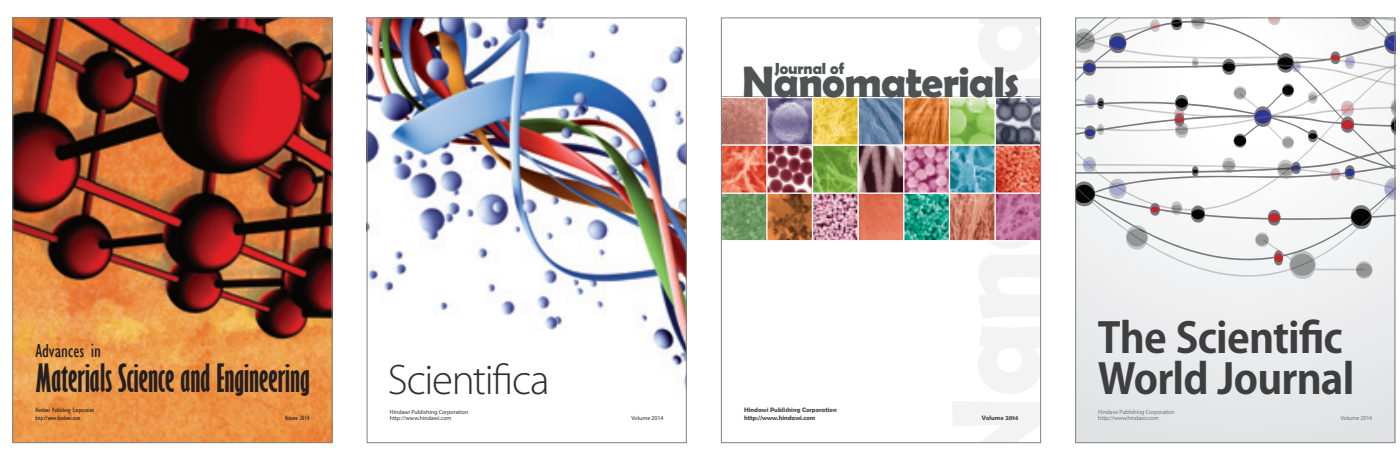

\section{The Scientific World Journal}
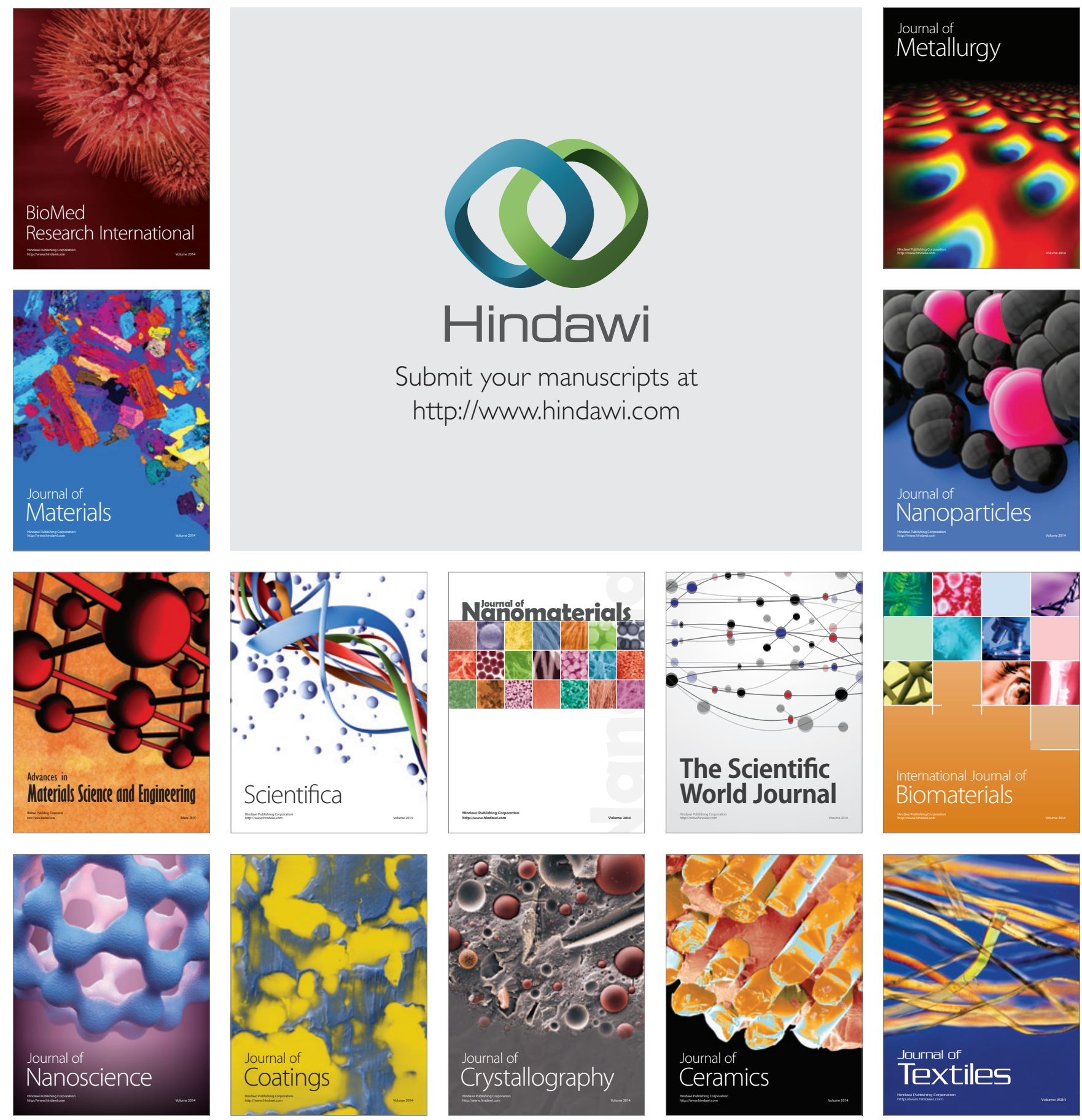